\title{
Scattered Interstitial Eosinophils Present
}

National Cancer Institute

\section{Source}

National Cancer Institute. Scattered Interstitial Eosinophils Present. NCI Thesaurus. Code C96214.

A morphologic finding indicating the presence of eosinophils scattered in the interstitial spaces of a tissue sample. 